\title{
CADEIA PRODUTIVA DO PROCESSAMENTO MECÂNICO DA MADEIRA - SEGMENTO DA MADEIRA SERRADA NO ESTADO DO PARANÁ
}

\author{
Willian Borelli Polzl $1^{1}$ \\ Anadalvo Juazeiro dos Santos ${ }^{2}$ \\ Romano Timofeiczyk Jr. ${ }^{2}$ \\ Priscilla Klingelfus Polzl
}

\begin{abstract}
RESUMO
A indústria de base florestal é muito importante no Paraná, o conhecimento de sua estruturação física e financeira e a interação de seus atores são vitais para o desenvolvimento do Estado. O segmento da madeira serrada tem importância crucial, econômica e socialmente, consumindo anualmente 6,6 milhões $\mathrm{m}^{3}$ de madeiras dos quais mais de $83 \%$ são de plantios florestais, gerando uma produção de 3 milhões de $\mathrm{m}^{3}$ de serrados. Atualmente o segmento no Estado conta com 3.700 empresas, das quais $75,6 \%$ são serrarias e $24,5 \%$ são de beneficiamento, ambas gerando 38.000 empregos diretos. Os principais pólos madeireiros estão nas microrregiões de Curitiba, Guarapuava, União da Vitória e Ponta Grossa, predominando as pequenas empresas. As exportações representam $5 \%$ do total de produtos exportados pelo Estado, gerando uma receita bruta anual de US\$ 155 milhões. A estruturação e fortalecimento do segmento da madeira serrada trarão resultados importantíssimos no campo econômico e social para o Paraná.

Palavras Chave: serrados, economia florestal, madeira
\end{abstract}

\section{THE SAW WOOD YIELD CHAIN IN PARANA STATE}

\begin{abstract}
The forest industry is very important to economy in Parana state. The economic and social structure of sawmills are related here. This view of productive chain starts in the consumer and finishes in the forest. Annually 6.6 million cubic metres of timber are consumed, which 3 millions refer to saw wood. Today there are 3,800 wood factories in Paraná (2,870 sawmills), generating 38.000 direct job posts. Curitiba, Guarapuava, União da Vitória and Ponta Grossa are the most important wood production zones in the state. The yield chain exportatied were US\$ 155 millions in 2001. It is very important to strengh and structure the sawnwood, because many people and economic factors are involved.

Key-words: forest economy, sawnwood, wood

\section{INTRODUÇÃO}

A importância da cadeia produtiva da madeira no Paraná pode ser constatada pela grande quantidade de indústrias de base florestal existente no Estado. Representa cerca de $2,57 \%$ do total de empresas, gerando $3,8 \%$ do total de

empregos no estado (MINISTÉRIO DO TRABALHO E EMPREGO - MTB, 2002).

Além disso, durante o ano de 2001, as exportações desta cadeia produtiva como um todo (madeira e papel) representaram $12 \%$ do valor total da exportação, que foi de US\$ 5,3 bilhões FOB, com a madeira se posicionando em segundo lugar, com $9,3 \%$
\end{abstract}

\footnotetext{
${ }^{1}$ Doutorando em Engenharia Florestal, UFPR.wpolzl@floresta.ufpr.br

${ }^{2}$ Professores do Departamento de Economia Rural e Extensão, UFPR, Brasil

${ }^{3}$ Mestranda em Engenheira Florestal, UFPR, bolsistaCNPq.
}

Encaminhado para publicação: 05/08/2002

Aceito para publicação: 10/06/2003 
(US\$ 493,7 milhões FOB), logo após o complexo soja, que contribuiu com $31,29 \%$ do valor exportado (INSTITUTO PARANAENSE DE DESENVOLVIMENTO ECONÔMICO E SOCIAL - IPARDES, 2002).

A cadeia da madeira reúne as atividades relativas à madeira e seus derivados. É caracterizada pelo conjunto de atividades que asseguram a produção, da colheita à transformação da madeira até o estágio onde esta última, por associação de seus derivados a outras matérias, perde a característica de constituinte essencial do produto (Selmany, 1993). Esta definição prevalece na França desde os anos 70.

A cadeia produtiva da madeira é composta basicamente por três cadeias: cadeia produtiva da madeira industrial (papel, painéis de alta densidade, aglomerados, Medium Density Fibreboard - MDF e Oriented Strand Board - OSB); cadeia produtiva da madeira para energia (lenha e carvão) e cadeia produtiva do processamento mecânico (serrados, compensados e laminados).

$\mathrm{O}$ estudo das cadeias produtivas inclui a localização das empresas, a quantificação da produção, as expectativas e objetivos dos agentes dos segmentos, a análise da sua estrutura de mercado, a análise do contexto organizacional e institucional onde ela se insere e a análise dos fluxos internos entre os segmentos em termos de custos, receitas, eficiência, limitações, oportunidades, ameaças e demandas.

O trabalho apresenta um panorama atual do segmento da madeira serrada no Paraná.

\section{MATERIAIS E MÉTODOS}

O presente estudo foi realizado no Estado do Paraná, região sul do Brasil.

As principais fontes de dados e informações para a análise do segmento da madeira serrada foram: Food and Agriculture Organization (FAO); Empresa Brasileira de Pesquisa Agropecuária (EMBRAPA); Instituto Brasileiro de Geografia e Estatística (IBGE); Instituto Brasileiro do Meio Ambiente e dos
Recursos Naturais Renováveis (IBAMA); Instituto Ambiental do Paraná (IAP); Secretarias de Estado da Fazenda (SEFA), da Agricultura e Abastecimento (SEAB) e da Indústria e Comércio (SEIC); Ministérios do Trabalho e Emprego (MTB), Desenvolvimento, Indústria e Comércio Exterior (MDIC), Meio Ambiente (MMA), Federação das Indústrias do Estado do Paraná (FIEP), bem como outras entidades do setor.

As informações sobre custos de produção, administração e comercialização foram encontradas junto a consultorias, empresas e associações representativas, bem como obtidas através de entrevistas a empresários. As relações entre a produção e produtividade, eficácia e eficiência das funções de produção do segmento foram obtidas através de revisão bibliográfica.

\section{METODOLOGIA}

A metodologia utilizada para a presente análise foi a seguinte: revisão da literatura, coleta e uso de dados secundários, elaboração de diagramas de fluxo e consultas a atores representativos da cadeia.

Para atingir os objetivos propostos nas análises de cadeias produtivas, o procedimento metodológico adotado baseia-se no Manual Metodológico para o SNPA - Prospecção de Demandas Tecnológicas, editado pela EMBRAPA (1995). Este procedimento estabelece a execução das seguintes etapas para a análise completa da cadeia produtiva:

1. Definição da localização e objetivos da cadeia produtiva;

2. Segmentação e detalhamento dos componentes da cadeia;

3. Análise do contexto organizacional e institucional;

4. Análise dos fluxos internos entre os componentes: custos, receitas; eficiência, limitações, oportunidades, ameaças e demandas;

5. Relatório final contendo medidas para consolidação e desenvolvimento da cadeia produtiva; 


\section{RESULTADOS E DISCUSSÃO}

\section{Estrutura da cadeia produtiva da madeira}

Segundo SELMANY (1993), a cadeia da madeira organiza-se em duas direções: uma longitudinal e outra transversal.

Do ponto de vista transversal, distinguem-se os processos sucessivos de transformação que levam a madeira de um estado bruto a um estado considerado como final. Essa sucessão compreende as seguintes atividades:

- Silvicultura;

- Colheita florestal;

- Primeira transformação;
- Segunda transformação;

- Terceira transformação;

- Consumidor Final.

Analisando-se o plano longitudinal, pode-se segmentar a Cadeia Produtiva da Madeira em três grandes cadeias, em função das distinções na utilização da madeira bruta (Figura 1). São elas:

- Energia;

- Processamento mecânico;

- Madeira Industrial.

O fluxo do segmento da madeira serrada, no seu corte longitudinal, pode ser visto na Figura 1.

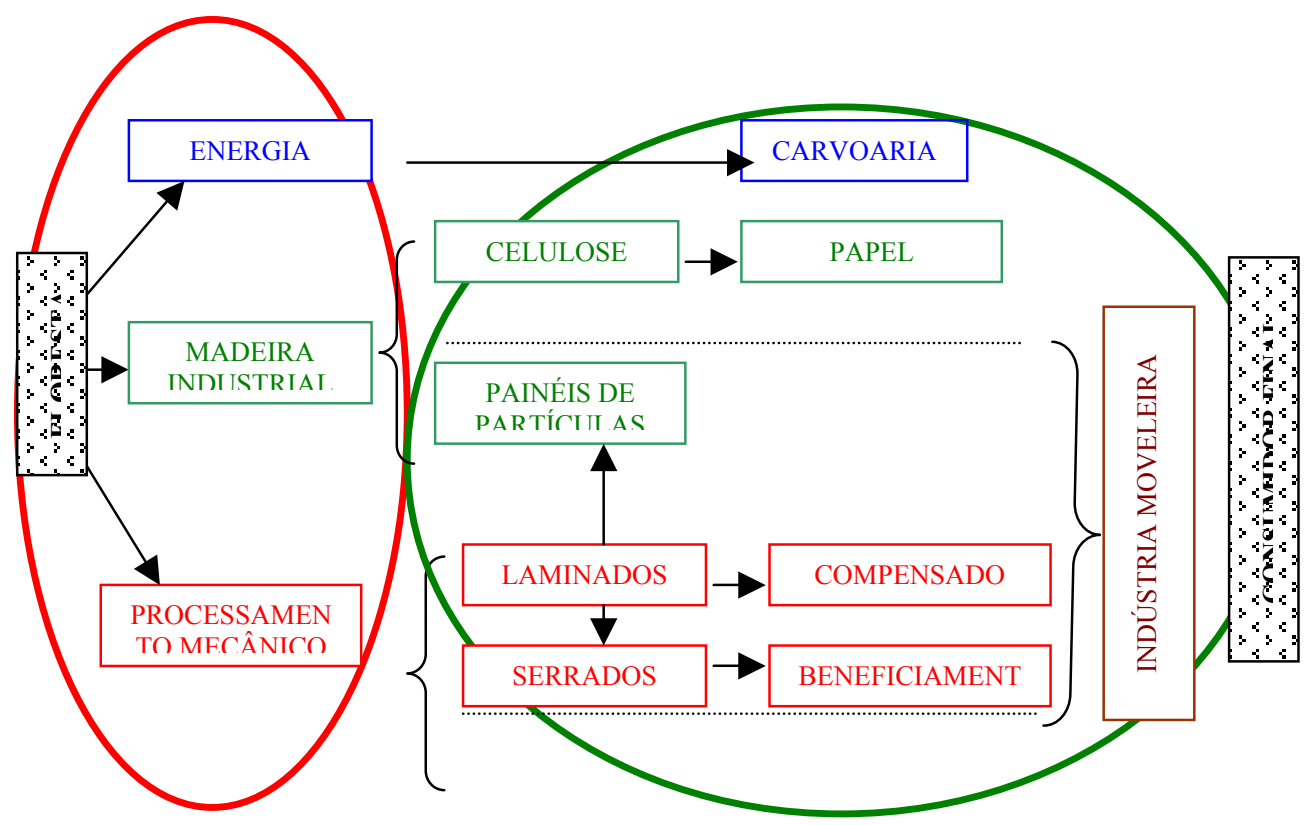

Figura 1: Fluxograma geral da cadeia produtiva da madeira no estado do Paraná

Figure 1 General flow of productive wood chain in parana state

\section{Situação florestal paranaense}

O Paraná possui uma superfície de 19,9 milhões de hectares, dos quais $8,6 \%$ estão sendo ocupados por florestas, $25,3 \%$ estão ocupados por vegetação secundária e $3,11 \%$ (620.489 hectares) são reflorestados (IAP, 1997).

Segundo IAP (2002), em 2001 foram explorados no Paraná 23,1 milhões $\mathrm{m}^{3}$ de madeira, dos quais 19 milhões $\mathrm{m}^{3}$ de Pinus, 1,6 milhões $\mathrm{m}^{3}$ de Eucalyptus, 1,1 milhões $\mathrm{m}^{3}$ de Araucária e 1,4 milhões $\mathrm{m}^{3}$ de outras angiospermas.

A tabela 1 mostra a participação do Paraná, em relação ao Brasil, no consumo de matéria-prima utilizada no processamento mecânico e na produção de madeira serrada. Observa-se que o Estado é responsável por $13 \%$ da madeira total consumida pela indústria de madeira serrada brasileira e produz $15 \%$ do total. 
Tabela 1: Participação do Paraná na utilização de matéria-prima florestal de processamento mecânico do Brasil

Table 1: Raw-material utilization in brazil and paraná's wood mechanical processing

\begin{tabular}{|c|c|c|c|}
\hline \multirow{2}{*}{$\begin{array}{c}\text { Usos } \\
\text { Processing }\end{array}$} & $\operatorname{Brasil}\left(\mathrm{m}^{3}\right)$ & Paraná $\left(\mathrm{m}^{3}\right)$ & \multirow[t]{2}{*}{$\%$} \\
\hline & $\operatorname{Brazil}\left(\mathrm{m}^{3}\right)$ & Paraná $\left(\mathrm{m}^{3}\right)$ & \\
\hline Matéria Prima Processamento Mecânico & 55.100 .000 & 9.000 .000 & 11,98 \\
\hline Matéria Prima para Serraria & 49.100 .000 & 6.600 .000 & 13,44 \\
\hline Matéria Prima de Reflorestamento & 15.100 .000 & 5.950 .000 & 39,40 \\
\hline Matéria Prima de Floresta Natural & 34.000 .000 & 650.000 & 1,91 \\
\hline Produção de madeira serrada & 19.640 .000 & 2.970 .000 & 15,12 \\
\hline
\end{tabular}

FONTE: SBS (2000); IAP (2002)

Em termos de floresta plantada, o Paraná possui a maior área com Pinus do país e a terceira com eucaliptos (IAP, 2002). O consumo de madeira de floresta natural no Paraná não passa de $2 \%$ do total consumido no país, evidenciando a redução significativa na área coberta pelas florestas naturais, como também ao seu caráter de formações secundárias, desprovidas de madeira para o segmento.

\section{FLUXO FÍSICO DA MADEIRA SERRADA}

Segundo o IAP (2002), o Paraná consumiu em 2001 cerca de 23,1 milhões de $\mathrm{m}^{3}$ de toras e toretes, destinadas as serrarias, laminação, fabricação de compensados, de painéis de partícula e de fibra, geração de energia bem como para fabricação de pastas, celulose e papel. A tabela 2, representando o fluxograma físico do segmento da madeira serrada, mostra o destino desta matéria prima.

Tabela 2: Fluxograma do segmento da madeira no Paraná, com ênfase na madeira serrada Table 2: Flow of saw wood sector in Parana state

\begin{tabular}{|c|c|c|c|c|c|c|c|c|c|c|}
\hline \multicolumn{3}{|c|}{ CONSUMO TOTAL POR ESPÉCIE } & \multicolumn{3}{|c|}{ CONSUMO TOTAL POR FINALIDADE } & \multicolumn{3}{|c|}{$\begin{array}{l}\text { CONSUMO TOTAL POR } \\
\text { ESPÉCIE }\end{array}$} & \multicolumn{2}{|c|}{ PRODUÇÃO TOTAL } \\
\hline $\begin{array}{l}\text { MATÉRIA } \\
\text { PRIMA }\end{array}$ & $(\%)$ & $\left(\mathrm{m}^{3}\right)$ & PROCESSO & $(\%)$ & $\left(\mathrm{m}^{3}\right)$ & ESPÉCIE & $(\%)$ & $\left(\mathrm{m}^{3}\right)$ & (\%) & $\left(\mathrm{m}^{3}\right)$ \\
\hline Total & 1,00 & 23.152 .300 & & & & & & & & \\
\hline & & & & & & Pinus & 0,75 & 4.950 .000 & 45,1 & 2.240 .000 \\
\hline Pinus & 0,82 & 18.984 .800 & Serrados & 21,60 & 6.600 .000 & Eucalyptus & 0,08 & 528.000 & 45,1 & 238.130 \\
\hline Eucalyptus & 0,07 & 1.620 .600 & & & & Araucária & 0,12 & 792.000 & 40,2 & 318.400 \\
\hline Araucária & 0,05 & 1.157 .600 & & & & Folhosa & 0,05 & 330.000 & 45,1 & 148.830 \\
\hline Folhosas & 0,06 & 1.389 .100 & & & & TOTAL & & 6.600 .000 & & 2.945 .360 \\
\hline
\end{tabular}

FONTE: IAP(2002)

Os rendimentos obtidos no processo de desdobro das toras em tábuas seguem os níveis de utilização nacionais, de $40 \%$ a $45 \%$, sendo ainda um processo com muitas perdas, inviabilizando a operação em muitas situações, indicando a grande defasagem tecnológica do parque industrial.
Nas regiões norte e oeste do Estado há uma grande carência de povoamentos florestais devido aos preços elevados da terra, com uso destinado agropecuária. Este fator, aliado à falta de tradição florestal, impossibilita a produção madeireira concentrando esta produção nas regiões central e sul do Paraná. 
Figura 2: Diagrama do fluxo físico do segmento da madeira serrada no Paraná Figure 2: lowchart of saw wood sector in Parana state

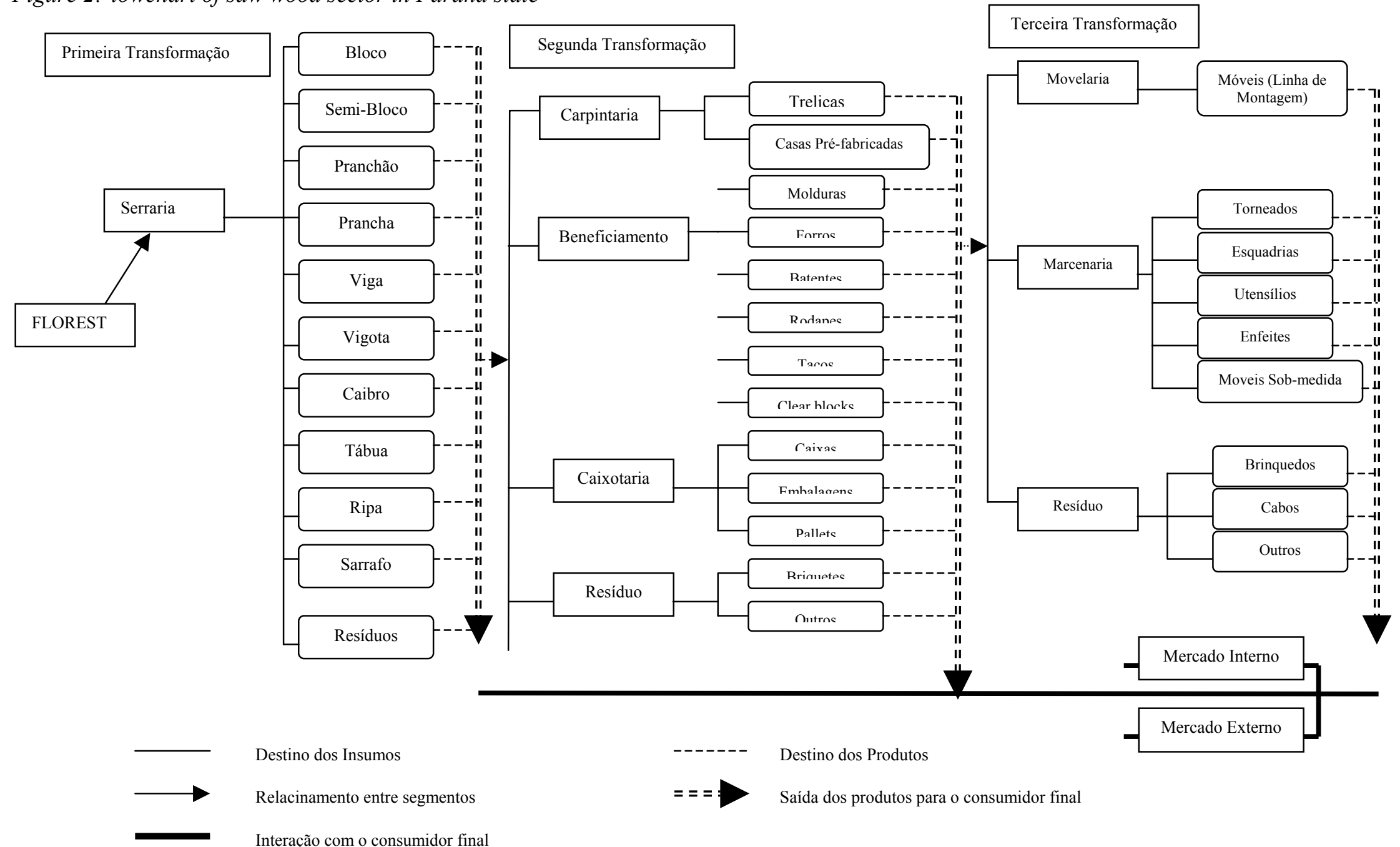


Os principais pólos de produção de madeira serrada são as microrregiões de Curitiba (764 empresas), Guarapuava (377 empresas), União da Vitória (286 empresas) e Ponta Grossa (219 empresas) (FIEP, 2002).

Segundo o IAP (2002), em 2000 haviam cerca de 1.093 empresas envolvidas na exploração florestal no Estado. As indústrias de primeira transformação contava com 1.521 empresas, gerando 23.387 empregos diretos. A indústria de segunda transformação contava com aproximadamente 1.031 empresas, gerando 12.576 empregos. A indústria de terceira transformação, (segmento moveleiro movelaria e marcenaria), seria composta por 498 empresas, contando com 10.355 empregados.

Segundo estudo da FIEP (2002), existem no segmento da madeira serrada 3.789 empresas, gerando 38.583 empregos diretos. Destes, a indústria de primeira transformação possui 2.864 empresas
(75,6\% do total do segmento), gerando 30.450 empregos diretos $(78,92 \%$ do total do segmento), enquanto que a indústria de segunda transformação possui 925 empresas $(24,4 \%$ do total do segmento), gerando 8.131 empregos diretos $(21,07 \%)$. As serrarias são em maior número $\mathrm{e}$ eqüivalem a $70 \%$ das empresas da cadeia produtiva no Estado, gerando cerca de 29.500 empregos (76,55\% da cadeia).

Atualmente a quantidade média de empregados por empresa na primeira transformação é de 10,6 empregados/empresa e na segunda transformação é de 8,8 empregados/ empresa, demonstrando a existência de grande número de micro e pequenas empresas. A diferença existente entre os dados (IAP, 2002) e (FIEP, 2002) deve-se, principalmente, às metodologias utilizadas pelas duas instituições.

$\mathrm{Na}$ tabela 3 pode-se ver o número de empresas e empregados do segmento no ano de 2002.

Tabela 3: Número de empresas e empregados no segmento da madeira serrada no Paraná

Table 3: Number of enterprises and employees in Parana saw wood sector

\begin{tabular}{l|rrrrr}
\hline Grau de manufatura das empresas & \multicolumn{2}{|c|}{ Empresas } & \multicolumn{3}{c}{ Empregados } \\
& Quantidade & \multicolumn{1}{c}{$\%$} & Quantidade & \multicolumn{1}{c}{$\%$} \\
\hline $1^{a}$ transformação & 2.864 & 75,6 & 30.452 & 78,93 \\
$2^{a}$ transformação & 925 & 24,4 & 8.131 & 21,07 \\
\hline Madeira Serrada & 3.789 & 100,0 & 38.583 & 100,00 \\
\hline FONTE: FIEP, 2002 & & & &
\end{tabular}

A segunda transformação possui cerca de $24,4 \%$ das empresas. Não foi possível a quantificação do número de empresas na terceira transformação (FIEP, 2002).

\section{Fluxo Financeiro}

O fluxo financeiro consiste em quantificar, em termos de valores monetários, os custos e as receitas que ocorrem dentro do processo produtivo da cadeia da madeira, bem como analisar a rentabilidade resultante das atividades desenvolvidas.

Com informações secundárias, somente parte do fluxo monetário do segmento da madeira serrada está descrito e detalhado, ou seja, a partir da aquisição da terra para plantios florestais até a saída da madeira serrada.
Para o gênero Pinus, por ser o mais importante em termos de consumo e produção de madeira no Estado, procedeuse a uma análise mais detalhada de custos e receitas.

O custo da madeira no pátio da serraria representa a soma dos custos da madeira em pé ( $>30 \mathrm{~cm}$ de DAP), da exploração florestal e do transporte da matéria-prima. Isso representa aproximadamente um custo de R\$33,00 $/ \mathrm{m}^{3}$ para atividade semi mecanizada (GOMES, 1999; FUNATURA/ITTO /IBAMA, 1995).

O custo da madeira de Pinus, no pátio da indústria de primeira transformação, utilizando métodos semi mecanizados, compõe-se por $53 \%$ do custo da madeira em pé e de oportunidade do uso 
da terra, $16 \%$ do custo de exploração e 31 $\%$ do custo de transporte.

As diversas regiões do Estado possuem diferentes distâncias dos pólos madeireiros, apresentando assim diferentes preços para madeira, em função das grandes variações nas distâncias de transporte. Outra causa desta variação é o seu provável uso (sortimento diamétrico).

A tabela 4 apresenta a variação no preço da madeira de 1997 a 2001.

Tabela 4: Variação no preço médio da madeira de pinus em pé e no pátio da serraria no estado do paraná para o período de 5 anos $(\mathrm{R} \$ / \mathrm{m} 3)$

Table 4: Price variation of in timber and wood to sawmill during 5 years in parana state

\begin{tabular}{lrr|r|r|r|r|r|r}
\hline & DIÂMETRO & 1997 & 1998 & 1999 & 2000 & 2001 & $\%$ & MÉDIA \\
\hline \multirow{3}{*}{ EM PÉ } & $10 / 20 \mathrm{~cm}$ & 12,23 & 9,42 & 12,75 & 11,66 & 14,87 & 17,76 & \\
& $20 / 30 \mathrm{~cm}$ & 16,63 & 16,28 & 17,04 & 20,10 & 23,11 & 28,04 & 22,89 \\
& $30 / 40 \mathrm{~cm}$ & 22,41 & 20,96 & 23,20 & 30,25 & 30,69 & 26,98 & \\
\hline \multirow{2}{*}{ NO PÁTIO } & $20 / 30 \mathrm{~cm}$ & 25,00 & 28,62 & 29,65 & 31,56 & 34,71 & 27,98 & \\
& $30 / 40 \mathrm{~cm}$ & 34,66 & 36,20 & 36,47 & 41,04 & 46,07 & 24,77 & 45,96 \\
& $>45 \mathrm{~cm}$ & 42,99 & 43,25 & 46,68 & 49,96 & 57,11 & 27,73 & \\
\hline TÁBUAS & 1 "x4"x 2,40 & 118,22 & 113,4 & 125,04 & 128,91 & 155,82 & 24,13 & \\
\hline
\end{tabular}

FONTE: SEAB (2002)

Ressalta-se que boa parte do produto exportado sai do Paraná via portos de Paranaguá, Itajaí e São Francisco do Sul. O volume exportado por portos foi de aproximadamente $\quad 130 \quad \mathrm{mil} \quad \mathrm{m}^{3}$ representando $6,6 \%$ do total de tábuas produzido no Estado. As principais espécies exportadas são Pinus spp, Araucaria angustifolia, Volchysia. (Cambará procedente de outros estados). Quase toda a produção de tábuas de madeira de angiospermas destina-se ao mercado externo, sendo os Estados Unidos, a Inglaterra e a Alemanha os principais compradores (IBAMA, 2001).

As exportações do segmento da madeira serrada pelos portos do Paraná movimentaram em 2001, cerca de US\$ 155 milhões (FOB), representando 5,66\% do total de produtos exportados pelo Estado. A madeira serrada responde por US\$ 155 milhões (FOB) e as molduras, obras de carpintaria e marcenaria, por cerca de US\$ 146 milhões (FOB), (MDIC, 2002).

\section{CONCLUSÕES}

Confirmando o estudo de RAMOS (1993), haverá falta de madeira reflorestada com diâmetros superiores e sem nó (madeira para serraria e principalmente laminação). Isto pode ser verificado pelo aumento nos preços médios do Estado nos últimos anos, este aumento é resultado da especulação de madeireiros que em algumas regiões mantém suas melhores árvores em pé e pela baixa oferta destas madeiras em outras regiões, provocando o aumento dos preços.

$\mathrm{O}$ baixo número médio de empregados por empresa (menos de 10 empregados por empresa), associado às baixas taxas de rendimento nos processos das serrarias $(<50 \%)$, indica a existência de muitas micro e pequenas empresas, com deficiências tecnológicas.

$\mathrm{O}$ consumo de madeira em toras e toretes no Estado vem crescendo passando de 19 milhões $\mathrm{m}^{3}$ em 1995, para 22 milhões em 1999, atingindo 23 milhões $\mathrm{m}^{3}$ em 2001.

Embora o segmento esteja crescendo, há muitas ações que podem torná-lo mais eficiente e conseqüentemente mais competitivo. Passando por reestruturações internas às empresas, reestruturações e adequações dos mercados regionais, estratégias conjuntas de comércio exterior, mas sempre com a figura do Estado como parceiro e facilitador destas reestruturações, tendo em vista a forte contribuição sócio-econômica que o segmento dá ao Paraná.

\section{BIBLIOGRAFIA}

EMBRAPA - DPD, Prospecção de Demandas Tecnológicas - Manual 
Metodológico para o SNPA, Brasília, 1995, 81p.

FEDERAÇÃO DAS INDÚSTRIAS DO PARANÁ (FIEP), Catálogo das indústrias no Paraná. Curitiba, FIEP, 2002, 380p. (atualizados em 2002).

FUNATURA/ ITTO/ IBAMA. Diagnóstico e avaliação do setor florestal brasileiro relatório da região sul. Curitiba, 1995, 503 p. Relatório Final.

GOMES, F. S. A seleção de regimes de manejo mais rentáveis em Pinus taeda $\mathbf{L}$. na produção de madeira para papel e celulose. Curitiba, 1999. 156 p..Tese de Mestrado.

INSTITUTO AMBIENTAL DO PARANÁ. Coletânea SERFLOR. Curitiba: SEMA/IAP/DIDEF, 1997. p. 6.

INSTITUTO AMBIENTAL DO PARANÁ (IAP). Dados sobre a cobertura e exploração de florestas no Paraná. Curitiba, 2002, Sistema SERFLOR, circulação restrita.

IBAMA - SUPES - PARANÁ. Exportação paranaense de produtos florestais, Curitiba, 2000, $4 \mathrm{p}$.

INSTITUTO PARANAENSE DE DESENVOLVIMENTO ECONÔMICO E SOCIAL (IPARDES). Economia Paranaense - Indicadores selecionados, Análise Conjuntural. Curitiba: 2002, V 24.n. $1-2$, p. 27
MINISTÉRIO DO TRABALHO E EMPREGO. Relação Anual de Informações Sociais (RAIS). Disponível em: <http://www.mtb.gov.br/Temas/RAIS/de fault.asp $>$ Acessado em 01/02/2002.

MINISTÉRIO DA INDUSTRIA E COMÉRCIO EXTERIOR, Sistema Alice de comércio exterior, Disponível em: <http://www.portaldoexportador.gov.br> Acesso em: maio 2002.

RAMOS, A. A. Perspectivas qualitativas e econômicas da produção florestal em sucessivas rotações. In. $\mathbf{1}^{\mathbf{0}}$ Congresso Florestal Pan-americano. Curitiba, 1993, p. 46.

$\begin{array}{lcr}\text { SECRETARIA DE } & \text { ESTADO } & \text { DA } \\ \text { AGRICULTURA } & \text { E } & \text { DO } \\ \text { ABASTECIMENTO } & \text { (SEAB/ } & \text { DERAL). } \\ \text { Acompanhamento de preços } & \text { agrícolas, } \\ \text { Curitiba, 2002,7 p. } & & \end{array}$

SECRETARIA DE ESTADO DA FAZENDA. Dados internos sobre Impostos estaduais, Curitiba, 1998. acesso restrito.

SELMANY, Y.. Analyse Des Flux Physique De Bois À L'interieur De La Filiére-Bois. Nancy. ENGREF. 1993. 200 p. Tese. Doutorado.

SOCIEDADE BRASILEIRA DE SILVICULTURA. Cadeia Produtiva de Madeira e Móveis. In: Revista Silvicultura. São Paulo, 2000, no. 83, p.16-21 